\title{
Política e Conflito Psíquico: Uma Pergunta sobre o Desejo
}

\author{
Guilherme Pimentel Jordão* \\ Pontifícia Universidade Católica de Minas Gerais - PUC Minas, Belo Horizonte, MG, Brasil \\ ORCID: https://orcid.org/0000-0002-8217-499X \\ Mariana Teixeira Duarte** \\ Pontifícia Universidade Católica de Minas Gerais - PUC Minas, Belo Horizonte, MG, Brasil \\ ORCID: https://orcid.org/0000-0003-2477-9728
}

\section{RESUMO}

Neste artigo, será introduzido o debate acerca da condição do sujeito estruturalmente dividido enquanto ator político. Pensando a política pelo prisma da ação, encontramo-nos com a pergunta kantiana: "Que devo fazer?". Diante dela, o sujeito desejante se vê embaraçado, tanto mais quanto maior for sua liberdade para decidir. A tentativa kantiana de instituir uma Lei universal como princípio ético da ação desvia a orientação da política do caminho da liberdade e entrega o seu destino aos ditames do Supereu. As consequências desse desvio se verificam em diferentes sistemas políticos e ratificam a afirmação de Lacan, segundo a qual a pergunta pelo que fazer não pode ser feita senão por aquele cujo desejo que se apaga. Se a pergunta acerca do que fazer continua ressoando para os sujeitos enquanto agentes políticos, o modo como decidem exibe, no conflito, a marca imposta pelo seu desejo. A psicanálise, de Freud a Lacan, vem ao auxílio dessa investigação, no diálogo com a filosofia moderna e a ciência política. Resta a pergunta se, diante do conflito, que testemunha a divisão do sujeito, o desejo, poderia ser, ele mesmo, o fio condutor da ação.

Palavras-chave: política, conflito psíquico, desejo, neurose.

\section{Politics and Psychic Conflict: A Question about Desire}

\begin{abstract}
In this article the debate about the condition of the structurally divided subject as a political actor will be introduced. As we think about politics from the perspective of the action, we find ourselves with the Kantian question: "What ought I do?" Before this question, the desiring subject finds oneself embarrassed. One finds oneself more embarrassed the greater is its liberty to decide. The Kantian effort to institute a universal Law as an ethical principle of the action changes the political orientation from the way of liberty and passes its destiny for Superego's rule. The consequences of this change is verifiable in different political systems and ratifies the assertion of Lacan, according to which the question about what to do cannot be made except for those whose desire is fading. Then, if the question about what to do continues to resonate for these subjects, as political agents, their decisions show, by the conflict, the mark imposed by desire. Freud's and Lacan's psychoanalysis helps us in this investigation on a dialog with modern philosophy and political science. One question
\end{abstract}

ISSN 1808-4281 
remains: whether desire itself could be, in spite of the conflict that denounces the subject's division, thread of the action.

Keywords: politics, psychic conflict, desire, neurosis.

\section{Política y Conflicto Psíquico: Una Pregunta sobre el Deseo}

\section{RESUMEN}

En este artículo, proponemos reflexionar sobre la condición del sujeto estructuralmente dividido como actor político. Pensando en la política a través del prisma de la acción nos encontramos con la pregunta kantiana: “¿Qué debo hacer?”. Frente a ella, el sujeto del deseo se avergüenza cuanto más mayor es su libertad para decidir. El intento kantiano de instituir una Ley universal como principio ético de acción desvía la orientación política del camino de la libertad y entrega su destino a los preceptos del Superyó. Las consecuencias de esta desviación se ven en diferentes sistemas políticos y confirman la afirmación de Lacan, según la cual la pregunta de qué hacer sólo puede plantearse aquel cuyo deseo se borra. Por lo tanto, si la pregunta sobre qué hacer continúa resonando con los sujetos como agentes políticos, la forma en que deciden muestra en el conflicto la marca impuesta por su deseo. El psicoanálisis de Freud a Lacan viene en ayuda de esta investigación, en diálogo con la filosofía moderna y la ciencia política. La pregunta sigue siendo si, frente al conflicto, que es testigo de la división del sujeto, el deseo podría ser el hilo conductor de la acción.

Palabras clave: política, conflicto psíquico, deseo, neurosis.

Os recentes acontecimentos na cena mundial revelaram o surgimento de fenômenos que podem ser lidos como um retorno de tendências autoritárias no campo da representação, trazendo à tona, no plano internacional, e mais recentemente na experiência brasileira, com o recuo da centro-esquerda ou a mutação de seu discurso em favor de perspectivas econômicas liberalizantes, expressões políticas de intolerância e racismo que se julgavam superadas no âmbito das democracias ocidentais. Esse tipo de acontecimento é visto com alguma surpresa entre especialistas, como também entre os cidadãos, que parecem observar, sob o manto das instituições democráticas, atitudes próprias das ditaduras.

Diante de tal observação, o momento político convoca os cidadãos a tomarem uma posição: convoca-os enquanto sujeitos. O silêncio diante do avanço autoritário se mostra uma postura cada vez mais problemática, não obstante a afirmação de qualquer posicionamento tenha força para despertar um campo de antagonismos para cada um, mesmo em seu círculo íntimo. A injunção para a tomada de posição torna-se, muito frequentemente, problemática 
também na esfera da consciência, posto que o compromisso político pede que se coloque a visada dos fins acima da coerência com certos valores próprios da esfera moral. Essa polaridade convoca o conflito psíquico e, com ele, a pergunta pela legitimidade da ação, que a aflição do sujeito consciente enuncia, como a solicitar da transcendência uma via de saída para os seus impasses: que devo fazer?

\section{A Política, entre o Consenso e o Conflito}

Que devo fazer? Essa pergunta, que aponta para o horizonte da ação e se pode associar ao domínio da política, é colocada por Kant no contexto da sua primeira crítica. Como tal, a mesma pergunta é retomada por Jaques-Alain Miller em seu diálogo com Lacan em Televisão (1974/2003), quando este último comenta: “Só pergunta 'que fazer?' aquele cujo desejo se apaga" (Lacan, 1974/2003, p. 539).

Que o plano da ação seja o mesmo da política, não obstante possa parecer claro de antemão, não prescinde que se faça tal afirmação sem melhor justificá-la do ponto de vista teórico. Designando a política como uma das três condições básicas para a manutenção da vida do homem, na vita activa, Arendt (2007) defende a tese de que ela se efetuaria mediante a ação. A autora apresenta tais considerações por meio da afirmação seguinte: "Todos os aspectos da condição humana têm alguma relação com a política; mas esta pluralidade é especificamente a condição - não apenas a conditio sine qua non, mas a conditio per quam de toda vida política" (Arendt, 2007, p. 15).

Argumentando que a ação, aliada ao discurso, constitui o fundamento incontornável da dimensão humana da vida, Arendt (2007) considera o termo agir, seja no sentido de iniciar, tomar iniciativa, seja no de "imprimir movimento a alguma coisa" (Arendt, 2007, p. 190). Pelo ato e pela palavra o homem se inseriria no mundo humano e, com isso, produziria para si um segundo nascimento (Arendt, 2007). Isso permite afirmar que "o preceito de liberdade foi criado ao mesmo tempo, e não antes, que o homem" (Arendt, 2007, p. 190). Interessaria à política, portanto, na linha do que propõe Hannah Arendt (2007), a ação cujo fim seria a própria efetividade do agir, sem que a visada de um outro resultado futuro pudesse vir a obscurecê-lo. Desse modo, resultaria que a ação em si mesma e a palavra seriam os fatores responsáveis por conferir à política a sua dignidade.

Tome-se, por outro lado, a afirmação de Bobbio, segundo a qual: “A Política e a moral estendem-se pelo mesmo domínio comum, o da ação ou da práxis humana" (Bobbio, 1998, p. 960). Distingue-as o mesmo autor pelo critério claro de que, enquanto a moral se regeria, 
quanto a seus fins, pela ideia de dever, a política teria como pressuposto da sua ação a intenção decidida acerca de uma determinada realização, cuja fórmula é classicamente enunciada no texto de Maquiavel. Tal realização é aí designada por Bobbio textualmente como desejo: "faz o que deves, a fim de que aconteça o que desejas" (Bobbio, 1998, p. 961).

Uma tal concepção de política, articulada com a resposta de Lacan, induz o leitor a raciocínios que assentarão muito mais no fundamento de um desejo insuspeito do que da vontade consciente, como talvez pressupusesse o imperativo da ética kantiana, consequência da elaboração de teor idealista desta última, para o que diz respeito àquilo que define a casuística de toda ação humana.

Se é somente para aquele cujo desejo se apaga que a pergunta kantiana acerca do que se deve fazer tem algum sentido, conclui-se sem dificuldade que aquele para quem o desejo é ativo, ou se mostra decidido, não caberia uma tal pergunta. À pergunta “que fazer?”, o desejo decidido enuncia, de sua parte, a certeza sobre a sua direção, ou a confirmação do que seria o ato a ser posto em exercício. Tornaria esse tipo de observação incauto o desejo que se diz decidido? $\mathrm{Ou}$, pelo contrário, todo ato determinado por uma escolha de desejo seria sempre acertado? O que quer dizer um desejo decidido? Um desejo do qual não se cede, certamente.

Não obstante, o caráter decidido do desejo não estará fundamentado na autonomia da vontade consciente, mas numa razão que subjaz aos atos que definem de modo inquestionável seu fazer. Quer dizer, mesmo que o desejo se mostre decidido, não fica claro o que se deve fazer, já que essa vontade nos é inconsciente. Tal como entre os ditames da moral e os fins da política, é possível afirmar que entre a vontade consciente do sujeito e seu desejo (mais ou menos decidido) devemos observar a existência do conflito. Se um sujeito é livre para escolher entre duas ou mais alternativas, a imposição da dúvida aí viria, se considerada uma concepção filosófica que herdamos da Ilustração, como uma patologia do desejo. Em consequência dessa dúvida, o sujeito se mostraria dividido e, consequentemente, poderia se tornar inibido, embaraçado, angustiado. Se recordarmos o esquema de Lacan (1962-63/2005) no seminário 10: A angústia, esse é o percurso que vai da máxima dificuldade ao extremo do movimento, precipitando-se, desse modo, num ato que deverá se colocar decididamente à distância do razoável.

É a partir dessas considerações que se faz possível a introdução de uma outra concepção de política, que é aquela proposta por Mouffe (2015). De início, essa autora distingue em seu trabalho dois tipos de exploração do campo da política: um primeiro que define como "política", o qual associa ao campo empírico; e um segundo, que denomina de "o político", sobre o qual nos deteremos mais amiúde neste trabalho, e que diria respeito aos 
fundamentos da sociedade, assim como se configuraria afim com a dimensão ontológica, ou do ser. Faz ainda uma distinção entre sua concepção e aquela de teóricos como Arendt, haja vista sua opção por pensar o político menos como "espaço de liberdade" - muito embora essa liberdade seja contrastada em Arendt (2007) com a perda da ilusão de soberania implicada pelo agir político e suas consequências não controláveis, em face da "condição humana da pluralidade" (p. 246) -, e mais como o domínio do conflito e do "antagonismo".

Mouffe (2015) critica a tentativa de teóricos liberais contemporâneos, como Giddens, Rawls e Habermas de, sob a justificativa de que haveria uma reconfiguração dos domínios de poder, com a hegemonia do capitalismo norte-americano no final do século XX, após o colapso do regime soviético, eliminar da política a ideia de adversário. A autora propõe que isto levaria, no fim das contas, ao lado do desbaratamento do conceito político de classe, à eliminação das diferenças políticas.

Neste mesmo trabalho, Mouffe (2015) reforça sua crítica aos teóricos acima, em particular a Giddens, a quem atribui a responsabilidade pela formulação das bases para um posicionamento político de centro-esquerda denominado Terceira Via: "O perigo de conceber a vida democrática como um diálogo é que podemos esquecer que sua principal realidade continua sendo a disputa" (p. 49). Sua ideia acerca do político como campo dos antagonismos visa a criar uma discrepância com a noção liberal de que o pluralismo democrático deveria sua sustentação à harmonia das diversas partes e à extinção do conflito, noção que, de acordo com a autora, abriria espaço para, com a indefinição das posições partidárias, como as que se identifica na distinção esquerda/direita, assumirem a dianteira do processo político identificações de caráter essencialista, como aquelas de matiz nacionalista, religioso ou étnico (Mouffe, 2015). Tal migração dos termos da disputa política acaba por alicerçá-la, cada dia mais, sobre o fundamento de categorias morais.

Diante da exigência de um "consenso universal baseado na razão" (Mouffe, 2015, p. 11), o político constituiria para o racionalismo liberal uma espécie de "ponto cego", posto que, ao se fundamentar sob o domínio do antagonismo - como insiste a autora, a partir da leitura de Carl Schmitt - o político se apresentaria como antítese do consenso racional. O contexto das relações antagônicas estaria, não obstante, conjugado com a vigência de uma ordem hegemônica, que se estabeleceria com vistas a ordenar o que de outro modo se percebe como contingente. Em outras palavras, a hegemonia que estabelece a ordem social é inerente ao equilíbrio que supera a ausência de leis de funcionamento do real, ao mesmo tempo em que permite situar os diferentes polos da situação antagônica antes descrita. Nesse sentido, a autora diferencia o social do político afirmando, acerca do primeiro, que se trata da "esfera 
das práticas sedimentadas" (Mouffe, 2015, p. 16), ao passo que caberia ao político instituir a hegemonia por meio do ato.

É certamente um ponto a ser considerado que o fato de que uma disputa de caráter antagônico, se não orientada de acordo com princípios maiores, com a primazia do benefício do conjunto sobre o gozo da vontade individual, poderia resultar num caótico campo de disputas imaginárias em que a eliminação do oponente dirigiria a ação de cada parte do jogo político. Nesse sentido, Mouffe (2015), como propõe em seu horizonte a defesa de uma prática política atenta à manutenção de uma ordem democrática, sugere que o antagonismo defendido por Schmitt ceda lugar a um outro tipo de relação entre os adversários no campo político, o qual denomina "agonismo" 1 . No agonismo, a despeito de que não se creia na utopia liberal que aponta para a solução racional dos conflitos, existe o reconhecimento, por parte de cada adversário, da legitimidade do outro.

É nesse sentido que Mouffe (2015) insiste na importância da "representação conflituosa" (p. 23) como essencial enquanto motor da mobilização política, a partir do que passa a considerar a identificação e o afeto como fatores indispensáveis para a adequada operação do político, em cânones democráticos. Emerge, nesse contexto, a noção de paixão, elemento sem o qual não se faz possível compreender ou atuar de modo político. Em consonância com a sua abordagem teórica, a autora define paixão como "os vários impulsos emocionais que se encontram na origem das formas de identificações coletivas" (Mouffe, 2015, p. 23).

Seguindo as reflexões então apresentadas por Mouffe (2015), seria possível questionar se a crise que atravessam as democracias no contemporâneo não se deveria, em parte, à falência da concepção, até então vigente nas democracias liberais, sobre a ação política como o exercício do consenso. Esta expectativa de unidade recalcaria o conflito próprio ao campo político, dando ensejo ao surgimento de antagonismos associados aos racismos de toda sorte, os quais se desenvolvem na lógica do que fora definido por Freud (1930/2006) como narcisismo das pequenas diferenças.

Miller (2011a), por sua vez, tece comentários a respeito do estado da democracia contemporânea, no que parte da afirmação lacaniana de que o inconsciente é a política, e encontra na tese de Gauchet o argumento para melhor definir esse estado da democracia como o encontro na cena pública dos opositores, sob o signo da pacificação e, quiçá, da homogeneidade. Fariam par, segundo essa definição, o espaço público pacificado, tolerante, palco do consenso, e o sofrimento privado do sujeito que se divide. Se a fórmula lacaniana, apropriada ao universo que se pauta pelo gozo, de que o sujeito é sempre feliz, entra nessa 
construção que nos apresenta Miller (2011a), talvez se possa endossá-la pensando que, na derrocada do que se delimitava, até meados do século XX, como sociedade disciplinar, já não há mais horizonte a ser buscado, ainda que, como propugnava Voltaire, efetivamente "se enforque o último rei com as tripas do último padre".

Haveria, na atualidade, uma injunção, por parte do Outro da civilização ${ }^{2}$, no sentido de fazer os sujeitos admitirem como próprios os valores da democracia liberal e do mercado, ao que uma certa posição de resistência se interpretaria como desejo de ser rejeitado, o que fundamenta, de acordo com Miller (2011b), a proposição de Lacan de que "o inconsciente é a política", assim declarada no interior do seminário A lógica da fantasia (Lacan, 196667/1998). Se o período do seminário de Lacan é já marcado pelo ambiente da Guerra Fria e, mais especificamente, do conflito no Vietnã - a partir do que Miller (2011b) destaca a citação: "Tratava-se de convencê-los de que estão errados em não quererem ser admitidos nos benefícios do capitalismo" (Lacan como citado em Miller, 2011b, p. 6) - não é difícil emparelhar as observações de Lacan com aquelas feitas por Freud a respeito dos neuróticos de guerra em 1921.

O que está em jogo então é a relação do sujeito em conflito com seu próprio desejo. A partir desse impasse, podemos propor que, na psicanálise, quando se pensa o ato político, pensa-se a respeito da problemática de um sujeito que, abandonando uma posição de gozo deve, por sua ação, necessariamente se dividir.

\section{A Dimensão da Ação Política sob o Primado do Sujeito da Razão}

No domínio do inconsciente freudiano, acossado pelas contradições próprias ao desejo, estar-se-ia muito distante do plano das ideias claras e distintas. Não se apresentaria facilmente, portanto, o acesso à verdade, tão à mão quando se trata do sujeito cartesiano, que pode então se ver tolhido por uma dúvida que lhe impede a ação. Menos próximo a Descartes, nesse ponto - a despeito de que lhe seja devedor, como assinala Lacan (1964/1998) ${ }^{3}$-, o inconsciente freudiano estaria, talvez, mais de acordo com a perspectiva de Spinoza, ressalvado o apelo deste último à noção de imanência. Nesse ponto específico, apoiamo-nos na seguinte afirmação de Balibar:

[...]Spinoza diz que o homem está sempre pensando (mas ele não pensa sempre adequadamente). Devemos acrescentar que ele sempre pensa sobre algo, tal como ele é sempre afetado pela alegria e pela tristeza nesses pensamentos, e pelos objetos 
desses pensamentos. Aqui Spinoza claramente antecipa Freud, cuja doutrina é caraterizada, menos pela importância do lugar dado à afetividade, que pela importância dada ao papel do pensamento na afetividade (Balibar, 2008, pp. 108-109, tradução nossa) ${ }^{4}$.

Para Spinoza, segundo esclarece Cottet, "não há vontade livre" (Cottet, 2015, p. 2), uma vez que seríamos "dilacerados em função de paixões contraditórias" (Cottet, 2015, p. 1). Resulta esse estado de coisas da noção admitida por Spinoza de que o fundamento da ideia diria respeito ao desejo manifesto do sujeito de permanecer em seu ser (Cottet, 2015). Aparece, nesse ponto, o importante conceito de conatus, que para Spinoza resume exatamente esse esforço do ser no sentido de perseverar em si próprio. Trata-se da essência de um ente posta em ato por intermédio do desejo.

Vale ressaltar que a filosofia de Spinoza, como apelo para um amálgama perfeito entre o pensamento e o afeto, jamais contemplaria a possibilidade do negativo no interior da essência, a não ser sob o signo do erro do entendimento. Nesse sentido, é para ele impossível conceber a proximidade, que podemos sem dificuldade constatar, entre a sua noção de conatus e a pulsão freudiana de morte: "O que é impensável para ele é aquilo que Freud chamou 'pulsão de morte': a ideia de que o conatus é baseado num ato fundamental de auto sabotagem" (Zizek, 1997, tradução nossa) ${ }^{5}$.

De acordo com Cottet (2015), o viés spinozista vai ao encontro das concepções newtonianas que marcaram o século XVIII no plano das ideias, no sentido em que identificam natureza e razão. Diz-se, a partir desse entendimento, que ambos, natureza e razão, ganham estatuto de causa determinante do agir ético. O segredo desse encontro reside naquilo que é identificado por Lacan (1966-67/1998) como a gênese da causa formal da ciência, a qual reside em sua concepção de verdade. Essa verdade da ciência é capaz de articular o ser do conatus, em alguma medida identificado com o domínio das paixões e da natureza, e a razão que calcula, elemento fundamental da ciência moderna, concebido a partir da física matemática.

Na confluência das ideias de natureza e de razão vê-se o surgimento, algum tempo depois, da pergunta de Kant acerca da existência de uma razão pura prática. Essa razão prática orientaria a vontade pela superação do interesse pessoal, conduzindo como tal ao cumprimento de princípios de natureza universal: fazer do princípio de sua ação o princípio que fundamentaria uma legislação universal. Essa que é, em linhas gerais, a máxima do Imperativo Categórico kantiano, submete o agir individual a princípios que não levam em 
conta o desejo e, como aprendemos a identificar com Lacan (1959-60/1988), vai na direção da Gute - Bem ou bondade, num sentido universal -, afastando-se do Wohl - bem no sentido de bem-estar: "Nenhum Wohl, que seja o nosso ou o do nosso próximo, não deve entrar como tal na finalidade da ação moral” (Lacan, 1959-60, p. 98). Se, por um lado, com o Wohl, se estaria no domínio do princípio do prazer, quando se trata da satisfação de um Bem identificado como Gute, certamente se aponta para um mais além, que será possível associar com os imperativos de gozo de natureza superegóica.

A partir da enunciação do seu Imperativo Categórico, Kant nos estaria convidando a considerar a máxima da ação moral como determinada por uma espécie de lei natural (Lacan, 1959-60/1988). Ao excluir da ação moral a dimensão dos sentimentos, Kant a estaria submetendo a uma Lei impessoal e incoercível, o que equivaleria a consentir com o domínio de um ser cujo pressuposto naturalista se opõe à política da psicanálise, que é fundada na falta-a-ser (Lacan, 1958/1998).

Kant, é interessante lembrar, desenvolve o seu argumento acerca da ética, na Crítica da razão prática, partindo da ideia de liberdade como condição da lei moral. Trata de vincular tal concepção de liberdade ao pressuposto de uma "consciência pura", que é a forma segundo a qual a liberdade se propõe no homem como princípio de causalidade, em contraposição ao determinismo da lei natural, à qual estaria aferrada a sua "consciência empírica". Essa distinção subjaz à sua afirmação de que o ser vive, conforme supomos, por si mesmo, em função da sua capacidade de influenciar a forma dos objetos da realidade, a partir de suas representações, no que denomina como a sua faculdade de desejar.

Se há, portanto, um fundamento do agir ético na crítica kantiana, este diz respeito a uma faculdade que se dissocia do horizonte das causas empiricamente determinadas para se basear na liberdade do sujeito da razão, excluído do seu campo de visada a perspectiva das paixões, como tais tratadas por transcendentes. Sendo assim, a regra moral, ou regra prática, deve sempre responder a uma prescrição proveniente da razão, sob a qual estaria determinada a lógica da intencionalidade no sujeito.

Trata-se, tal como designa expressamente o filósofo, no caso desta regra, de um dever - ein Sollen - o qual implica que, "se a razão determinasse totalmente a vontade, a ação ocorreria indefectivelmente segundo essa regra" (Kant, 1959, p. 38). Tal definição constituiria essa regra como um imperativo, que na forma da lei teria por função determinar a vontade em si mesma, sem que tivesse em vista qualquer efeito consentâneo com a produção do prazer, posto que esta última condição não seria suficiente para estabelecer tal imperativo enquanto lei. Esta lei é o princípio responsável pela sustentação da existência de uma "faculdade 
superior de desejar", oposta a uma outra, dita inferior, ligada como tal à materialidade empírica.

Deve-se, contudo, reconhecer que essa concepção ética de Kant, muito embora fundada, em última instância, no impacto recebido da ciência de Newton, não se desprende de um idealismo muito afim com o sujeito da razão esclarecida, que reedita ao seu modo o sujeito do Cogito cartesiano. Em Kant, portanto, a existência dos objetos dependerá da suposição do sujeito cognoscente, a partir da intuição, nele presente, do espaço e do tempo. Resta, não obstante, inalcançável o conhecimento da Coisa em si - das Ding - que Kant mantém em suspenso. Caberá, desse modo, ao sujeito transcendental a tarefa de criação das leis que regem a natureza.

Não obstante aparentados, o cogito cartesiano e o primado do dever na Ética kantiana destoam, uma vez que aquele é criticado por Kant em sua condição de substância. Essa crítica significa que o sujeito cartesiano é reenviado ao horizonte da ação e, como tal, ao ser questionado acerca do que deve fazer, deverá responder por um princípio que o transcende e, desse modo, divide-o. Sobre o sujeito ético em Kant não se abateria a menor divisão, a despeito de que possa legislar, ele mesmo, acerca dos princípios de suas ações. Desse modo, concorda-se aqui com a observação de Miller (2000), de acordo com a qual a autonomia, que é princípio fundador da ética kantiana, articular-se-ia com a divisão do sujeito, com o sujeito barrado: "A autonomia do sujeito significa o sujeito barrado enquanto que separável dos seus condicionamentos objetivos" (Miller, 2000, p. 25, tradução nossa ${ }^{6}$ ).

É em função do postulado problemático da liberdade que a filosofia kantiana se apresenta alicerçada sobre uma condição de sujeito dividido. Ainda que a liberdade seja o princípio fundamental dessa ética ilustrada, ela, em si mesma, supõe a existência de uma alternativa que, grosso modo, pode-se definir como: "a felicidade ou o dever". A felicidade, enquanto princípio subjetivo, atrelado ao universo empírico, não serviria como princípio de uma legislação universal, e seu uso como fundamento para uma política de Estado só poderia redundar ou no despotismo, ou na revolta (Rossi, 2006).

Uma fórmula como a do Imperativo kantiano pode ser vinculada à autoridade do Supereu, cujas divisas, a despeito de, por um lado, respaldarem a ação moral do sujeito, suprimirem, por outro, a sua liberdade. Esse paradoxo do funcionamento da consciência moral no contexto da política é verificável naquilo que é próprio do fascismo. Sua lógica, como sugere a etimologia da palavra, que alude ao feixe unido, a fascio littorio, supõe o privilégio do Um, em detrimento da singularidade, e o assujeitamento da vontade individual aos desígnios de um ente coletivo. A ética fundada no universal da Razão prática concorreria, 
desse modo, para o ideal do "fascista totalitário", definido por Gentile (2019): [...] O fascista totalitário havia anulado o individualismo egoísta, o interesse privado, a busca do prazer pessoal, para viver unicamente, com espírito ascético e guerreiro, numa comunidade unida pela fé no Duce" (p. 81, tradução nossa ${ }^{7}$ ).

Como Kant buscasse uma certeza matemática que pudesse definir o modo pelo qual se deveria atuar, o resultado de sua pesquisa ética seria a forclusão de todo o desejo (Miller, 2000). Desse modo, tende-se a, seguindo Miller (2000), confirmar que a premissa da ética de Kant apontaria para a colocação do Bem no lugar daquilo que ocasionaria o mal-estar, e daquilo que, do ponto de vista do sujeito, faz-lhe bem, no sentido do bem-estar ou do prazer, como o seu próprio mal.

O que se apresenta, a partir de Kant, conforme se observa, é o processo de expurgar o sujeito desejante de Spinoza, colocando em seu lugar o sujeito da razão, o qual se mostra transcendente com relação ao que se poderia identificar como natureza humana (Cottet, 2015). No mundo que nos oferece Kant, na Crítica da razão prática, extinguem-se todos os objetos, toda a matéria - objeto para as formas inferiores ou patológicas de desejar -, restando, no horizonte da razoabilidade da ação humana, a pura forma (Miller, 2000).

Consequência disso é que se vê recalcado, em sua concepção ética, o desejo do sujeito, cuja pergunta - “o que devo fazer?” - é a própria expressão do dito recalque. No comentário de Kant, por ocasião da Crítica da razão pura, após postular as três perguntas de onde se extrai a questão inicial deste trabalho - "Que posso saber? Que devo fazer? Que me é permitido esperar?" - o autor submete a resposta à segunda dessas questões ao arbítrio de uma vontade transcendente dotada de razão:

[...] este sistema da moralidade que se recompensa a si própria é apenas uma ideia, cuja realização repousa sobre a condição de cada qual fazer o que deve, isto é, de todas as ações dos seres acontecerem como se brotassem de uma vontade suprema, que compreendesse nela ou subordinasse a ela todos os arbítrios particulares (Kant, 2001, pp. 654).

À pergunta que concerne à moral, e por extensão à política, o sujeito não responderia senão por enunciado alheio a seu próprio ser, onde, por estarem instaladas as inquietantes “inclinações”, não submetidas à Lei universal da razão, concentrar-se-ia tudo o que deveria ser evitado em termos da ação. 
Excluindo essas inclinações por meio dessa adaptação à racionalidade, não se evidenciaria outra coisa que a presença de "uma máscara que encobr[iria] o imperativo de gozar do fantasma, [posto que] não haveria outro gozo" (Laurent, 1984, p. 41, tradução nossa

${ }^{8}$ ). Observar-se-ia, a partir dessa direção, uma resposta à suposição do bem em geral, fundada na fantasia do sujeito. Ela deformaria a própria ação e suas consequências, pela influência de uma boa vontade próxima da sugestão. A psicanálise certamente não se apresentaria à salvo nesse jogo, inserida em uma época em que, como assinala Lacan (1958), a felicidade se tornou um fator da política. Corre o risco de apelar, inadvertidamente, a um tal expediente supergóico, por meio do qual tentaria mostrar ao sujeito, através da janela da fantasia, de que forma a natureza lhe sorri.

Tratar-se-ia, portanto, para a psicanálise, de assumir uma direção distinta da ética do dever, e da obrigação de bem compreender. O horizonte da análise, no plano da ética, se aferraria mais ao desejo, que enquanto metonímia da falta-a-ser (Lacan, 1958/1998, p. 629), não oferece garantias de satisfação ou de felicidade àquele que a ela se submete.

Essa interferência do desejo anuncia que o horizonte da ação não poderá ser reconhecido senão no encolhimento da liberdade, justamente onde se localiza o conflito por meio do qual se alcança, no inconsciente, a alternativa que separa o gozar e o agir.

\section{O Inconsciente e o Conflito Psíquico a partir de Freud}

Se, como descrito anteriormente, a dimensão do conflito é indispensável ao plano da reflexão política, no interior da concepção psicanalítica de sujeito o conflito psíquico é, do mesmo modo, deveras importante. Na teoria freudiana, a concepção de conflito atravessa o conjunto das considerações clínicas e metapsicológicas, do início ao final da extensa obra do autor. Do ponto de vista econômico, esse conflito se apresenta de maneira pregnante quando se recorre aos artigos de Freud, e um em especial chama atenção pela importância que assume, ainda mais pela rearticulação teórica conhecida, quando entra em cena o conceito de pulsão de morte. Trata-se do texto Além do princípio do prazer (Freud, 1920/2006).

Neste, o dualismo pulsão sexual e pulsão do eu cede lugar a um outro modo de dualismo que embaralha a estabilidade da noção de princípio do prazer. Tomando em consideração o primeiro par de opostos, reconhece-se em sua dialética uma disputa entre as demandas de satisfação que partem do inconsciente e a unidade egóica, uma vez que esta última pressupõe um acúmulo de restrições à satisfação, a fim de que se adeque às exigências ideais que o compõem enquanto todo coerente. 
A despeito de que essas satisfações sejam, de modo reiterado, repelidas pelo eu pela via do recalque, não raramente conseguem lograr êxito em se realizar, em geral por intermédio de formações sintomáticas. Desse modo, o conflito se mostra em sua forma mais aguda, representado por "um prazer que não pode ser sentido como tal" (Freud, 1920/2006, p. 21). Este prazer proibido teria origem no recalcado, que faria contraponto ao eu consciente, repetindo as iniciativas de dar vazão às suas tendências, sempre que a oportunidade se fizesse presente. A reprodução das condições originais do complexo paterno facilitaria a expressão dessas tendências como atuações durante o tratamento analítico (Freud, 1920/2006).

É certo, como ressalta Freud, que na transferência, além das primitivas situações de prazer, é também revivida toda sorte de experiências desprazerosas. Haveria, portanto, uma estrutura capaz de sobrepujar em sua força o princípio do prazer e se fazer atuar na forma de uma compulsão à repetição. Freud (1920/2006) associa esta mesma compulsão ao impulso que leva os neuróticos de guerra a repetir, em sonho, a experiência de seus traumas.

Seguindo de perto os fenômenos da compulsão à repetição, Freud (1920/2006) elabora a hipótese acerca da existência de uma pulsão, cuja tendência seria a manutenção de um estado primitivo de existência, uma perseveração em seu próprio ser, de forma que enuncia de modo categórico: "Parece, então que um instinto é um impulso inerente à vida orgânica, a restaurar um estado anterior de coisas" (Freud, 1920/2006, p. 47). Em vista dessa afirmação, testará a hipótese subsequente de que todas as pulsões são conservadoras, o que será, não obstante, contrastado em face da análise das pulsões sexuais, logo a seguir. Característica curiosa a se notar em face dessa descrição é que as pulsões de morte ou conservadoras são aqui identificadas por Freud (1920/2006) às pulsões do Eu, em contraponto às pulsões sexuais, assim ditas pulsões de vida, as quais, de acordo com o texto, levam ao desenvolvimento, sempre influenciadas, é bom que se recorde, pela tensão provocada por forças exteriores ao sujeito.

$\mathrm{O}$ contraponto entre as tendências do Eu e as tensões exercidas do exterior sobre os sujeitos é também tema do trabalho de Freud a respeito da psicologia das massas (Freud, 1921/2006). As considerações contidas nessa obra são, sem sombra de dúvida, importantes quando se considera a preponderância do conflito psíquico no interior da política. A certa altura, no capítulo V, está destacada por Freud uma passagem que assinala que, assim como a presença do líder amado faz invariavelmente parte da estrutura do grupo, a ausência de vínculo libidinal entre seus membros e o dito líder poderia ser causa, para o grupo, de sua derrocada. Aponta o autor, de acordo com tais ideias, a seguinte ponderação: 
Sabemos que as neuroses de guerra que assolaram o exército alemão foram identificadas como sendo um protesto do indivíduo contra o papel que se esperava que ele desempenhasse no exército e, de acordo com a comunicação de Simmel (1918), o duro tratamento dos soldados pelos seus superiores pode ser considerado como a principal entre as forças motivadoras da moléstia. (Freud, 1921/2006, pp. 107)

Entende-se, desse modo, conforme é observado por Freud (1921/2006), ao longo deste capítulo, que os laços mantidos pelo sujeito com relação ao seu grupo são dependentes das relações que estabelece com o seu líder. Para exemplificar essa afirmação, Freud aponta para o fenômeno do pânico, o qual descreve a desintegração que decorre do medo em que são capturados os membros de um grupo, uma vez que se perca o laço libidinal que propiciava a sua união, estrutura que explica, de modo análogo, a ansiedade neurótica.

Seguindo essa mesma linha de raciocínio, Freud (1921/2006) observa que é a força do laço grupal que condiciona, por outro lado, o surgimento dos fenômenos de intolerância, cujo exemplo mais notório se refere à intolerância religiosa, mas que atinge outros grupos fortemente identificados a uma instância superior ideal. Desse modo, completa Freud (1921/2006):

Se hoje a intolerância não mais se apresenta tão violenta e cruel como em séculos anteriores, dificilmente podemos concluir que ocorreu uma suavização nos costumes humanos. A causa deve ser antes achada no inegável enfraquecimento dos sentimentos religiosos e dos laços grupais que deles dependem (Freud, 1921/2006, pp. 110).

A reflexão freudiana coloca, conforme se vê, a manifestação neurótica como enunciado de significado político. Ainda que esse seja o momento do ápice do poder disciplinar no período moderno, no que está em notório contraste com o momento contemporâneo da cultura, é escusado marcar a relevância de perceber o sintoma como expressão de um desejo politicamente implicado, e que, talvez no momento presente, conforme antes se viu, possa se manifestar por meio de um afeto ansioso ou depressivo, bem como nos muitos fenômenos de violência vivenciados pelos sujeitos no cotidiano.

O conflito psíquico, ao menos quando se trata da neurose, faz-se diante da impossibilidade de realização pulsional frente às repressões impostas pela cultura. A partir da convivência social e inserção na cultura, cedo o sujeito aprende que nem sempre a satisfação das suas tendências é a melhor opção, uma vez que delas pode resultar alguma punição. Em 
decorrência dessa ponderação, o sujeito decide adiar a obtenção de prazer, por meio do princípio da realidade.

A construção do princípio da realidade, fruto da interação com a alteridade ou com o Outro, torna possível consolidar a existência autônoma de um Eu (Freud, 1920/2006). Se inicialmente a criança incorpora tudo o que é percebido por ela como bom, pela via oral, é necessário que expulse o que não é bom - Austoßung -, atribuindo a si apenas aquilo que lhe parece benéfico, que assume ou reconhece como próprio - Bejahung (Freud, 1925/2006). Podem-se definir, portanto, para a adequada composição da realidade, três processos vinculados ao princípio do prazer: negação [Austoßung], afirmação [Bejahung] e suprassunção [Aufhebung]. Nas neuroses, admite-se que a suprassunção estaria vinculada à formação da fantasia, que tem como função realizar o enquadre para o desejo do Outro, ficção subjetiva que dá estrutura à verdade de cada sujeito.

É preciso, então, primeiro negar para poder, em seguida, tomar do campo do Outro, assim constituído, algo para si. Do ponto de vista da teoria das pulsões, esse entendimento já aparece no texto de Freud, A pulsão e seus destinos (1915/2006): "O ódio, enquanto relação com os objetos, é mais antigo que o amor. Provém do repúdio primordial do ego narcisista ao mundo externo com seu extravasamento de estímulos" (Freud, 1915/2006, p. 143). É notório que somente pela exclusão do que lhe parece mau é que o sujeito como tal se constitua, e que, somente por influência da cultura, possa tolerar conviver e dialogar com a realidade que não lhe proporciona prazer de forma imediata.

$\mathrm{Na}$ neurose, a construção da realidade partiria do conflito entre as duas instâncias topográficas definidas por Freud em seu aparelho psíquico, o Eu e o Isso, sendo que haveria, com a mediação da fantasia, certa equivalência entre o $\mathrm{Eu}$ e a realidade. Uma terceira instância é introduzida por Freud (1923/2006) ao lado do Isso e do Eu. Vindo, a princípio, em auxílio do princípio de realidade, ela trabalha, junto ao $\mathrm{Eu}$, para o recalque, retirando da consciência as representações de natureza sexual que não se façam compatíveis com o Ideal do eu. Essa instância, que condiciona tal julgamento, é o Supereu (ou Superego).

Cabe recordar que o Supereu é o produto do conflito psíquico entre o Eu e o Isso, e que se instala na criança como corolário da crise edípica, sendo tomado, com relação a esta, na conta de herdeiro. Tratar-se-ia, como advogava Freud (1923/2006), de uma forma de diferenciação do Eu inconsciente que, ao final do processo edípico, após haver incorporado os objetos primitivos, abandonava-os enquanto alvos libidinais. Tais objetos comporiam aquilo que viria a se instalar na forma do Supereu, representante dos ideais vinculados aos objetos antes investidos pelo Isso, nomeadamente os ideais paternos. 


\section{O Destino da Política e a Escolha da Neurose}

O estudo das neuroses apresenta-se, tomadas em consideração as noções da metapsicologia freudiana relativas ao conflito psíquico, como ponto de chegada para as discussões sobre a dimensão subjetiva do ato político, antes postuladas. Seguindo Freud (1921/2006), no que ele entende como interseção necessária entre psicologia individual e psicologia social, compreende-se que é possível explicar as alterações na subjetividade pensada no coletivo e suas formas de construção, pela leitura das soluções encontradas pelos sujeitos no interior das neuroses. Dessa forma, ainda que com a necessária ressalva de que não se pretende aqui reduzir o sujeito político a etiquetas diagnósticas ou tipos clínicos, podese considerar que ser, por exemplo, partidário de uma política conservadora ou revolucionária, como sugere Coelho dos Santos (2017), aponta para as circunstâncias misteriosas da escolha da neurose.

Partindo desse pressuposto, retomemos o debate freudiano a respeito do Supereu, sua influência sobre o recalque e suas consequências nas neuroses. Essa instância, podemos dizer que é preponderante no contexto da neurose obsessiva, já que nela o sujeito se instala no lugar que é próprio à dita instancia. É esse o lugar a partir do qual se vigia e se critica, e que é possível delinear de modo claro na conscienciosidade obsessiva, própria do que foi conceituado como caráter anal, e que faz conviverem, lado a lado, a mais estrita obediência e o mais violento espírito de revolta.

A neurose obsessiva é certamente uma estrutura que pode conter um programa de trabalho quando se trata de discutir as noções contemporâneas de política, dada a sua forma particular de lidar com os afetos de amor e ódio, conforme se comenta largamente nos textos psicanalíticos. O obsessivo estaria inibido em seu amor pela presença do ódio, posto que a demanda de amor o induziria a apresentar diante do outro a sua castração, obrigado que estaria a dar o que não tem (Zenoni, 2008). Desse modo, na neurose obsessiva estaria presente a agressividade como estratégia para a anulação do desejo, o qual, quando falham as inibições, vem à tona na forma do ato impulsivo. Uma leitura política a partir dessa chave poderia ajudar a explicar certos fenômenos de intolerância, observados num contexto aparentemente destinado a um incremento quanto aos parâmetros de democracia e civilidade.

A presença desse elemento de agressividade se coloca na ordem do dia para mortificar o desejo. Verifica-se, com Cottet (2015), que a ambivalência obsessiva é a "inibição do ódio" que fundamenta seu desejo de destruir o outro, parceiro ao qual está certamente identificado. Por meio dessa identificação é que o obsessivo se posta no exterior, a observar a si próprio 
(em cena). É o narcisismo que joga um papel primordial nessa relação entre o obsessivo e seu outro, que só pode querer destruir.

Esse aspecto serve para figurar como contraponto à tese cartesiana, segundo a qual quando se tem ideias claras e distintas não se verifica hesitação (Cottet, 2015). A teorização freudiana coloca, portanto, em xeque os pressupostos de uma tal moral ilustrada, ao reconhecer que repousa no conflito o motor da ação do sujeito. Também nos diversos relatos de casos de histeria em Freud é digno de nota que as suas jovens pacientes se utilizam de fórmulas surgidas no conflito para fundamentar o seu agir, que é posto em ato, sintomaticamente, em forma de solução de compromisso entre duas instâncias com tendências opostas. Pode-se afirmar, desse modo, que o inconsciente joga, nesse ponto, um papel de instância oculta de regulação dos atos do sujeito, tal como fazia a Razão com relação ao sujeito moral kantiano.

A histeria tem como característica fundamental constituir o desejo como insatisfeito. No interior dessa forma de se orientar, o sujeito goza da insatisfação e escolhe se identificar à posição masculina para se perguntar e construir um saber sobre o desejo do Outro. A formulação dessa pergunta sobre o desejo do Outro acaba por ensejar o esclarecimento do seu próprio desejo. Dessa forma, a caracterização do discurso histérico aparece mais marcadamente, para os sujeitos, em duas das posições que podem assumir, quais sejam: a de requerente ou de insatisfeito.

Essa particularidade do desejo na histeria não se passaria sem que também implicasse consequências no contexto dos fenômenos de massa. Nesse caso, a identificação desses sujeitos, por meio do amor a um Mestre, poderia proporcionar, quer a reprodução de características próprias a seus líderes, quer a sua feroz contestação. Se pensarmos na própria estrutura do desejo, é a partir desta inquietação, proveniente da insatisfação, que será possível uma reinvenção ou mudança. Destarte, essa forma de se colocar enquanto sujeito nos ensina que o conflito é inevitável e necessário à ação política.

Se fizermos com Lacan o percurso que vai do desejo ao gozo, obter-se-á, como tal, a noção de que a impotência diante do conflito psíquico se coloca em substituição à impotência diante do furo no real, que constitui o gozo e que está fora da lógica interditora e alienante do Outro. Não ceder do seu desejo, aforismo que se extrai do Seminário de Lacan (195960/1988) sobre a ética, poderia, mais do que a uma política da liberação das pulsões, fazer referência a uma experiência de natureza dialética, com respeito ao que se apresenta no gozo como mortificante. Seu sentido último seria o de não recuar frente ao Outro, diante do qual o sujeito, na neurose, teme depor suas armas. 


\section{Conclusão}

Entende-se, a partir do percurso desse trabalho, que a via do debate freudiano, mais além da clínica, pode nos oferecer subsídios para pensar o ato político dentro dos parâmetros da subjetividade. $\mathrm{O}$ estudo das neuroses traz de forma clara o que parece envolto em fumaça quando se pensa a respeito dos fenômenos políticos que, no contemporâneo, denunciam certa contradição entre os interesses dos grupos e as escolhas a que eles são induzidos no campo político democrático. Nesse sentido, a dimensão do conflito se coloca como inerente ao espaço público, assim como o é no privado. Se a pergunta acerca do que fazer continua ressoando para os sujeitos enquanto agentes políticos, o modo como decidem exibe, no conflito, a marca imposta pelo seu desejo, queiram eles ou não saber algo a respeito disso. Assim, diante do conflito que evidencia a divisão do sujeito, o desejo seria o fio condutor da ação. Se, com Lacan, podemos dizer que o inconsciente é a política, esta, como tal, será sempre guiada pela política do desejo.

\section{Referências}

Arendt, H. (2007). A condição humana (10a ed.). Rio de Janeiro: Forense Universitária.

Balibar, E. (2008). Spinoza and Politics. London-New York: Verso.

Bobbio, N. (1998). Política. In N. Bobbio, N. Matteucci, \& G. Pasquino (Orgs.), Dicionário de Política (11a ed.). Brasília: UNB.

Coelho dos Santos, T. (2017). A psicanálise é politicamente revolucionária ou conservadora? Revista aSEPHallus de Orientação Lacaniana, 12(23), 4-22. doi: 10.17852/1809709x.2019v12n23p4-22

Cottet, S. (2015). Ne demande "que faire", que celui dont le désir s'éteint. Bordeaux: UFORCA. Recuperado de https://www.lacan-universite.fr/ne-demande-que-faire-quecelui-dont-le-desir-seteint-2/

Freud, S. (2006). Os Instintos e suas vicissitudes. In J. Strachey (Ed.), Obras psicológicas completas de Sigmund Freud: Edição standard brasileira (J. Salomão, Trad., Vol. 14, pp. 115-144). Rio de Janeiro: Imago. (Obra original publicada em 1915)

Freud, S. (2006). Além do princípio de prazer. In J. Strachey (Ed.), Edição standard brasileira das obras psicológicas completas de Sigmund Freud (J. Salomão, Trad., Vol. 18, pp. 11-75). Rio de Janeiro: Imago. (Obra original publicada em 1920) 
Freud, S. (2006). Psicologia de grupo e análise do ego. In J. Strachey (Ed.), Obras psicológicas completas de Sigmund Freud: edição standard brasileira (J. Salomão, Trad., Vol. 18, pp. 77-154). Rio de Janeiro: Imago. (Obra original publicada em 1921)

Freud, S. (2006). O Ego e o Id. In J. Strachey (Ed.), Obras psicológicas completas de Sigmund Freud (J. Salomão, Trad., Vol. 19, pp. 15-80). Rio de Janeiro: Imago. (Obra original publicada em 1923)

Freud, S. (2006). A negativa. In J. Strachey (Ed.), Obras psicológicas completas de Sigmund Freud: Edição standard brasileira (J. Salomão, Trad., Vol. 19, pp. 261-269). Rio de Janeiro: Imago. (Obra original publicada em 1925)

Freud, S. (2006). O mal-estar na civilização. In J. Strachey (Ed.), Edição standard brasileira das obras psicológicas completas de Sigmund Freud (J. Salomão, Trad., Vol. 21, pp. 65-147). Rio de Janeiro: Imago. (Obra original publicada em 1930)

Gentile, E. (2019). Quién es fascista. Madrid: Alianza.

Kant, E. (1959). Crítica da Razão Prática. São Paulo: Edições Publicações Brasil.

Kant, I. (2001). Crítitca da Razão Pura. Lisboa: Fundação Calouste Gulbenkian.

Lacan, J. (1998). A direção do tratamento e os princípios do seu poder. In J. Lacan, Escritos (pp. 591-652). Rio de Janeiro: Jorge Zahar. (Obra original publicada em 1958)

Lacan, J. (1988). O Seminário, livro 7: A ética da psicanálise. Rio de Janeiro: Jorge Zahar. (Obra original publicada em 1959-60)

Lacan, J. (2005). O seminário, livro 10: A angústia. Rio de Janeiro: Jorge Zahar. (Obra original publicada em 1962-63)

Lacan, J. (1998). Posição do inconsciente. In J. Lacan, Escritos (pp. 843-864). Rio de Janeiro: Jorge Zahar. (Obra original publicada em 1964)

Lacan, J. (1998). A ciência e a verdade. In J. Lacan, Escritos (pp. 869-891). Rio de Janeiro: Jorge Zahar. (Obra original publicada em 1966-67).

Lacan, J. (2003). Televisão. In J. Lacan, Outros Escritos (pp. 508-543). Rio de Janeiro: Jorge Zahar. (Obra original publicada em 1974).

Lalande, A. (1997). Agonistique. In Lalande, A, Vocabulaire technique et critique de la philosophie (4a ed., pp. 33). Paris: Quadrige/PUF.

Laurent, E. (1984). Seminario sobre La dirección de la cura y los principios de su poder. In E. Laurent, Concepciones de la cura en psicoanalisis (pp. 5-54). Buenos Aires: Manantial.

Miller, J.-A. (2000). Lakant. Barcelona: Escuela Lacaniana de Psicoanalisis del Campo Freudiano. 
Miller, J.-A. (2011a). Intuições milanesas. Opção Lacaniana online nova série, 2(5), 1-15.

Recuperado de http://www.opcaolacaniana.com.br/pdf/numero_5/Intui\%C3\%A7\%C3\%B5es_milanes as.pdf

Miller, J.-A. (2011b). Intuições Milanesas II. Opção Lacaniana online nova série, 2(6), 1-21. Recuperado a partir de http://www.opcaolacaniana.com.br/pdf/numero_6/Intuicoes_Milanesas_II.pdf

Mouffe, C. (2015). Sobre o político. São Paulo: Martins Fontes.

Rossi, M. (2006). Aproximações ao pensamento político de Immanuel Kant. In A. A. Boron (Org.), Filosofia Politica Moderna: De Hobbes a Marx (pp. 189-211). São Paulo: USP.

Zenoni, A. (2008). Le plus-de-jouir dans la névrose obsessionnelle. La Cause du désir, revue de psychanalyse, 3(70), 143-154. Recuperado de https://www.cairn.info/revue-lacause-freudienne-2008-3-page-143.htm

Zizek, S. (1997). Philosophy: Spinoza, Kant, Hegel and... Badiou!. Recuperado de https://www.lacan.com/zizphilosophy1.htm

\section{Endereço para correspondência}

\section{Guilherme Pimentel Jordão}

Avenida Dom José Gaspar, 500, Coração Eucarístico, Belo Horizonte - MG, Brasil. CEP 32630-000

Endereço eletrônico: gpjordao@yahoo.com.br

Mariana Teixeira Duarte

Avenida Dom José Gaspar, 500, Coração Eucarístico, Belo Horizonte - MG, Brasil. CEP 32630-000

Endereço eletrônico: psicologamarianateixeira@gmail.com

Recebido em: 05/08/2019

Reformulado em: 08/06/2020

Aceito em: 15/07/2020

\section{Notas}

* Psiquiatra. Mestre em Psicologia. Doutorando em psicologia na PUC Minas. Experiência na área de Psicologia, com ênfase em Psicanálise e saúde mental.

** Psicóloga. Mestre em psicologia. Experiências na área de psicologia clínica, com ênfase em Psicanálise e Saúde Mental.

${ }^{1}$ Agonismo: Palavra de origem grega ( $\left.\dot{\alpha} \gamma \omega v ı \sigma \mu o ́ s\right)$, substantivo nominal, que designa rivalidade, ou disputa que se mantém com tenacidade, teimosia. A agonística ( $\alpha \gamma \omega v ı \sigma \tau \imath \kappa \eta)$, termo que está associado às disputas atléticas, 
no campo das doutrinas filosóficas se referiria à orientação para a luta como instrumento para o progresso (Lalande, 1997).

${ }^{2}$ Com a expressão "Outro da civilização" faz-se alusão ao lugar dos ideais e dos significantes por meio dos quais os sujeitos se identificam para poderem tomar parte em certa realidade. Provêm desses significantes mestres da civilização as fórmulas mediante as quais o Supereu obriga a gozar dos seus benefícios, que podemos supor de ordem política, econômica, entre outras. A presença do Supereu pode ser considerada indissociável da instituição da ordem civilizada.

3 "O sujeito, o sujeito cartesiano, é o pressuposto do inconsciente, como demonstramos no devido lugar" (Lacan, 1964/1998, p. 853).

${ }^{4}$ [...] Spinoza says that man is always thinking (but he does not always think adequately). We might add that he always knows something, just as he is always affected by joy or sadness at his thoughts and fo $r$ the objects of his thoughts. Here Spinoza clearly anticipates Freud, whose doctrine is characterised less by the importance it places on affectivity than by the importance it places on the role of thought in affectivity.

5 What is unthinkable for him is what Freud called "death drive": the idea that conatus is based on a fundamental act of self-sabotaging.

${ }^{6}$ La autonomía del sujeto significa el sujeto tachado en tanto que separable de sus condicionamientos objetivos.

${ }^{7}$ El fascista totalitario habría anulado el individualismo egoísta, el interés privado, la búsqueda del placer personal, para vivir únicamente, con espirito ascético y guerrero, en una comunidad unida por la fe en el Duce. 8 ... es una máscara que encubre el imperativo de gozar del fantasma, pues no habrá otro goce.

Este artigo de revista Estudos e Pesquisas em Psicologia é licenciado sob uma Licença Creative Commons Atribuição-Não Comercial 3.0 Não Adaptada. 